\title{
Nodal staging affects adjuvant treatment choices in elderly patients with clinically node-negative, estrogen receptor-positive breast cancer
}

\author{
A. Laws MD, ${ }^{*}$ R. Cheifetz MD MEd, ${ }^{\dagger}$ R. Warburton MD, ${ }^{\dagger \neq}$ C.E. McGahan MSc, ${ }^{\S}$ J.S. Pao MD, ${ }^{\ddagger}$ \\ U. Kuusk MD, ${ }^{\ddagger}$ C. Dingee $M D_{,}^{\ddagger}$ M.L. Quan MD MSc, ${ }^{*}$ and E. McKevitt MD MEd ${ }^{\dagger \ddagger}$
}

\begin{abstract}
Background In response to Choosing Wisely recommendations that sentinel lymph node biopsy (SLNB) should not be routinely performed in elderly patients with node-negative (cN0), estrogen receptor-positive (ER+) breast cancer, we sought to evaluate how nodal staging affects adjuvant treatment in this population.
\end{abstract}

Methods From a prospective database, we identified patients 70 or more years of age with cN0 breast cancer treated with surgery for ER+ HER2-negative invasive disease during 2012-2016. We determined rates of, and factors associated with, nodal positivity ( $\mathrm{pN}+$ ), and compared the use of adjuvant radiation (RT) and systemic therapy by nodal status.

Results Of 364 patients who met the inclusion criteria, 331 (91\%) underwent SLNB, with 75 (23\%) being pN+. Axillary node dissection was performed in 11 patients $(3 \%)$. On multivariate analysis, tumour size was the only factor associated with $\mathrm{pN}+(p=0.007)$. Nodal positivity rates were $0 \%, 13 \%, 23 \%, 33 \%$, and $27 \%$ for lesions preoperatively sized at $0-0.5 \mathrm{~cm}, 0.5-1 \mathrm{~cm}, 1.1-2.0 \mathrm{~cm}, 2.1-5.0 \mathrm{~cm}$, and more than $5.0 \mathrm{~cm}$. Compared with patients assessed as node-negative, those who were $\mathrm{pN}+$ were more likely to receive axillary RT (lumpectomy: $53 \%$ vs. $1 \%, p<0.001$; mastectomy: $43 \%$ vs. $2 \%, p<0.001$ ), and adjuvant systemic therapy (endocrine: $82 \%$ vs. $69 \%$; chemotherapy plus endocrine: $7 \%$ vs. $2 \%, p=0.002)$.

Conclusions Of elderly patients with cN0 ER+ breast cancer, $23 \%$ were pN+ on SLNB. Size was the primary predictor of nodal status, and yet significant rates of nodal positivity were observed even in tumours preoperatively sized at $1 \mathrm{~cm}$ or less. The use of RT and systemic adjuvant therapies differed by nodal status, although the long-term oncologic implications require further investigation. Multidisciplinary input on a case-by-case basis should be considered before omission of SLNB.

Key Words Breast cancer in elderly patients, sentinel lymph node biopsy, predictors of nodal positivity, adjuvant radiation, adjuvant endocrine therapy

\section{BACKGROUND}

The Society of Surgical Oncology's Choosing Wisely campaign recommends that patients more than 70 years of age with clinically node-negative (cN0), estrogen receptor-positive (ER+) breast cancer (BCa) should not routinely undergo sentinel lymph node biopsy (SLNB) ${ }^{1}$. That recommendation is based on randomized controlled trials that demonstrated no difference in overall or BCa-specific survival in elderly patients with early вСа who underwent axillary dissection compared with no axillary surgery ${ }^{2,3}$. All patients in the trials received adjuvant endocrine therapy.

Elderly patients tend to be frailer, with associated comorbidities. The risks of axillary surgery, including general anesthesia and lymphedema, could be more frequent and of greater consequence in that population ${ }^{4}$. As a result, avoiding SLNB is an attractive option. However, information gained from axillary staging might influence other 
treatment decisions for elderly patients, including adjuvant radiation therapy (RT) and systemic therapies ${ }^{5-8}$, and therefore the role for SLNB in this population remains unclear.

Current patterns of axillary surgery and the influence of axillary staging on adjuvant treatment decisions in elderly patients have not been characterized at our institution or in the Canadian context. Axillary RT is routinely offered for patients with 1 or more positive lymph nodes, based on regional and distant recurrence benefits and the disease-free survival benefit demonstrated in the MA.20 and European Organisation for Research and Treatment of Cancer 22922/10925 trials ${ }^{9,10}$. We hypothesized that, even in elderly patients, the staging information gained from SLNB is routinely used to select patients who will derive benefit from regional nodal RT and those who could safely avoid that treatment through documented negative nodal status. Given the American Society of Clinical Oncology recommendation that all postmenopausal patients with ER+ BCa receive adjuvant endocrine therapy ${ }^{11}$, we suspect that nodal status has less effect on adjuvant systemic treatment.

In the present study, we aimed to evaluate the potential effect of applying the Choosing Wisely recommendations at our institution: that is, not routinely offering SLNB for elderly patients with cN0 ER+ BCa. To evaluate the proportion of patients in whom the knowledge of positive nodal status would be lost, we identified predictors of nodal positivity using preoperatively known variables, and we determined absolute rates of axillary metastases in various subgroups. To characterize how subsequent treatment might be affected in the absence of routine axillary staging, we evaluated the current effect of nodal status on adjuvant therapy in patients receiving SLNB.

\section{METHODS}

We identified all patients 70 years of age and older who underwent surgery for invasive BCa at Mount Saint Joseph Hospital in Vancouver, British Columbia, from January 2012 to December 2016. We excluded patients with recurrent BCa, palliative-intent surgery, neoadjuvant therapy, and disease that was clinically node-positive, or ER-negative or HER2-positive (or both). The cohort was identified from a prospectively-maintained database that captures all BCa surgeries performed at our institution. Demographic, surgical, and pathology variables were collected from the surgical database. Available preoperative tumour factors included size and focality. Histologic subtype, grade, and receptor status were based on the final pathology report. Adjuvant treatment, including RT and endocrine and systemic therapies, was obtained from the BC Cancer Registry and the Breast Cancer Outcomes Unit.

Descriptive statistics are used to characterize the cohort's oncologic features and to evaluate practice patterns of axillary surgery. We used the chi-square or Fisher exact test for categorical variables and the median score test for continuous variables to compare clinical, tumour, and surgical characteristics for patients who did and did not undergo axillary surgery. In the subset of patients treated with SLNB, logistic regression analysis was performed to identify factors associated with axillary metastases. We then used logistic regression to examine absolute rates of axillary metastases in subgroups of patients stratified by any significant variables. For patients with available adjuvant therapy data, we compared the use of RT, chemotherapy, and endocrine therapy by nodal status (positive vs. negative). We further stratified the use of adjuvant therapies by age. Any patients with missing data were excluded from the analyses. Statistical significance was defined as $p<0.05$. Approval for the study was obtained from the Research Ethics Board, University of British Columbia.

\section{RESULTS}

We identified 513 patients 70 or more years of age who underwent curative treatment for primary invasive $\mathrm{BCa}$ during the study period. We excluded 59 patients (11.5\%) who were clinically node-positive at presentation, 6 (1.2\%) who received neoadjuvant therapy, and 84 (16.4\%) who had ER-negative or HER2-positive disease. The analyzed cohort therefore consisted of 364 patients with a median age of 75 years (range: 70-102 years). The most common presentation was a breast mass or imaging abnormality (both $n=175,48.1 \%)$. On preoperative assessment, most patients had lesions $2 \mathrm{~cm}$ or smaller in size $(n=230,63.2 \%)$ and unifocal disease ( $n=323,88.7 \%)$. Histology showed primarily invasive ductal carcinoma ( $n=322,88.5 \%)$, and low- or intermediate-grade disease ( $n=311,85.4 \%$ ). Initially benign histology or ductal carcinoma in situ on core biopsy in 26 patients $(7.1 \%)$ was upstaged to invasive cancer after excisional surgery. Final surgery was breast-conserving (BCS) in 219 patients $(60.2 \%)$, total mastectomy in $130(35.7 \%)$, and total mastectomy with reconstruction in 15 (4.1\%).

\section{Patterns of Axillary Surgery}

In 33 patients $(9.1 \%)$, no axillary surgery was performed. Compared with patients who received axillary surgery (Table I), the former patients were older $(p=0.004)$, more likely to be treated with BCS $(p=0.008)$, and more likely to have been upstaged to invasive cancer after excisional biopsy $(p<0.001)$. Stratified by age, SLNB was performed in 149 of 158 patients less than 75 years of age (94.3\%), in 112 of 117 aged $75-79$ years (95.7\%), and in 70 of 89 aged 80 years or more $(78.7 \%)$. Of 331 patients receiving SLNB, 75 (22.7\%) had axillary metastases. Axillary lymph node dissection (ALND) was performed in 11 patients (14.7\%): 8 at the initial surgery and 3 in a delayed fashion. The indications for ALND were suspicious intraoperative findings $(n=7)$, more than 2 positive sentinel nodes on final pathology $(n=2)$, non-mapping sentinel node $(n=1)$, and suspicion of residual or recurrent disease $(n=1)$.

\section{Factors Associated with Axillary Metastases on SLNB}

The multivariate analyses (Table II) included 324 of 331 patients $(97.9 \%)$ with SLNB performed and no missing data. Only preoperative tumour size ( $p=0.007)$ was significantly associated with axillary metastases. Age, histologic subtype, multifocality, and grade were not statistically significant in the model. Absolute rates of axillary metastases on SLNB by preoperative tumour size were $0 \%$ ( 0 of 20 ) for $0-0.5 \mathrm{~cm}, 13.1 \%$ (11 of 84 ) for $0.5-1 \mathrm{~cm}, 23.3 \%$ (24 of 103) for $1.1-2.0 \mathrm{~cm}, 33.0 \%$ (37 of 112) for $2.1-5.0 \mathrm{~cm}$, and $27.3 \%$ (3 of 11) for more than $5 \mathrm{~cm}$ (Figure 1). 
TABLE I Clinical, tumour, and surgical characteristics of elderly patients with clinically node-negative, estrogen receptor-positive, HER2-negative breast cancer by use of axillary surgery

\begin{tabular}{|c|c|c|c|}
\hline \multirow[t]{2}{*}{ Characteristic } & \multicolumn{2}{|c|}{ Axillary surgery } & \multirow{2}{*}{$\underset{\text { Value }}{p}$} \\
\hline & None & SLNB & \\
\hline Patients $(n)$ & 33 & 331 & \\
\hline Age (years) & & & 0.004 \\
\hline Median & 80 & 75 & \\
\hline Range & $70-102$ & $70-92$ & \\
\hline Presenting complaint $[n(\%)]$ & & & 0.92 \\
\hline Mass & $16(48.5)$ & $159(48.0)$ & \\
\hline Imaging abnormality & $17(51.5)$ & $158(47.7)$ & \\
\hline Other breast symptom & 0 & $14(4.3)$ & \\
\hline $\begin{array}{l}\text { Dx on preoperative } \\
\text { core biopsy }[n(\%)]\end{array}$ & & & $<0.001$ \\
\hline Benign or DCIS & $12(36.4)$ & $13(3.9)$ & \\
\hline Invasive & $20(60.6)$ & $318(96.1)$ & \\
\hline No biopsy & $1(3.0)$ & 0 & \\
\hline Preoperative size [n (\%)] & & & 0.12 \\
\hline $0-0.5 \mathrm{~cm}$ & $6(18.2)$ & $20(6.1)$ & \\
\hline $0.5-1.0 \mathrm{~cm}$ & $8(24.2)$ & $84(25.4)$ & \\
\hline $1.1-2.0 \mathrm{~cm}$ & $9(27.3)$ & $103(31.1)$ & \\
\hline $2.1-5.0 \mathrm{~cm}$ & $10(30.3)$ & $112(33.8)$ & \\
\hline$>5.0 \mathrm{~cm}$ & 0 & $11(3.3)$ & \\
\hline Unknown & 0 & $1(0.3)$ & \\
\hline Histologic type [n (\%)] & & & 0.13 \\
\hline Ductal & $28(84.9)$ & $294(88.8)$ & \\
\hline Any lobular component & $4(12.1)$ & $36(10.9)$ & \\
\hline Other & $1(3.0)$ & $1(0.3)$ & \\
\hline Preoperative focality $[n(\%)]$ & & & 0.87 \\
\hline Unifocal & $29(87.9)$ & $294(88.8)$ & \\
\hline Multifocal or multicentric & $4(12.1)$ & $37(11.2)$ & \\
\hline Grade $[n(\%)]$ & & & 0.69 \\
\hline Low & $11(33.3)$ & $113(34.1)$ & \\
\hline Intermediate & 19 (57.6) & $167(50.5)$ & \\
\hline High & $2(6.1)$ & $50(15.1)$ & \\
\hline Unknown & 0 & $1(0.3)$ & \\
\hline Final breast surgery $[n(\%)]$ & & & 0.03 \\
\hline Breast-conserving & $27(81.8)$ & $192(58.0)$ & \\
\hline Mastectomy & $5(15.2)$ & $125(37.8)$ & \\
\hline $\begin{array}{l}\text { Mastectomy with } \\
\text { reconstruction }\end{array}$ & $1(3.0)$ & $14(4.2)$ & \\
\hline Axillary surgery [n (\%)] & & & NA \\
\hline None & $33(100)$ & 0 & \\
\hline SLNB & 0 & $320(96.7)$ & \\
\hline ALND & 0 & $11(3.3)$ & \\
\hline Pathologic T stage $[n(\%)]$ & & & 0.15 \\
\hline pT0 (no residual disease) & 0 & $4(1.2)$ & \\
\hline pT1a & $6(18.2)$ & $20(6.0)$ & \\
\hline pT1b & $7(21.2)$ & $76(23.0)$ & \\
\hline pT1c & $10(30.3)$ & $133(40.2)$ & \\
\hline pT2 & $10(30.3)$ & $90(27.2)$ & \\
\hline pT3 & 0 & $7(2.1)$ & \\
\hline Unknown & 0 & $1(0.3)$ & \\
\hline
\end{tabular}

\begin{tabular}{|c|c|c|c|}
\hline \multirow[t]{2}{*}{ Characteristic } & \multicolumn{2}{|c|}{ Axillary surgery } & \multirow{2}{*}{$\underset{\text { Value }}{p}$} \\
\hline & None & SLNB & \\
\hline Pathologic $\mathrm{N}$ stage $[n(\%)]$ & & & NA \\
\hline $\mathrm{pNO}$ & NA & $256(77.4)$ & \\
\hline $\mathrm{pN} 1$ & & $70(21.1)$ & \\
\hline $\mathrm{pN} 2$ & & $3(0.9)$ & \\
\hline $\mathrm{pN} 3$ & & $2(0.6)$ & \\
\hline Positive SLNs $[n(\%)]$ & & & NA \\
\hline 0 & NA & $256(77.4)$ & \\
\hline 1 & & $55(16.6)$ & \\
\hline 2 & & $16(4.8)$ & \\
\hline 3 & & $4(1.2)$ & \\
\hline Radiation therapy $[n(\%)]$ & & & 0.08 \\
\hline Local & $10(30.3)$ & $124(39.7)$ & \\
\hline Local and regional & $1(3.0)$ & $38(12.2)$ & \\
\hline None & $22(66.7)$ & $150(48.1)$ & \\
\hline Systemic therapy $[n(\%)]$ & & & $<0.001$ \\
\hline Endocrine & $14(42.4)$ & $225(72.1)$ & \\
\hline $\begin{array}{l}\text { Chemotherapy and } \\
\text { endocrine }\end{array}$ & 0 & $10(3.0)$ & \\
\hline None & $13(39.4)$ & $67(21.5)$ & \\
\hline Unknown & $6(18.2)$ & $10(3.2)$ & \\
\hline
\end{tabular}

SLNB = sentinel lymph node biopsy; $\mathrm{Dx}=$ diagnosis; $\mathrm{DCIS}=$ ductal carcinoma in situ; $\mathrm{ALND}=$ axillary lymph node dissection; $\mathrm{NA}=$ not applicable; $\mathrm{SLNs}=$ sentinel lymph nodes.

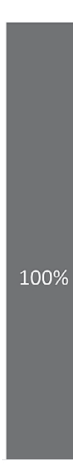

T1a

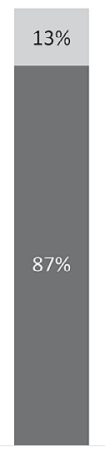

T1b

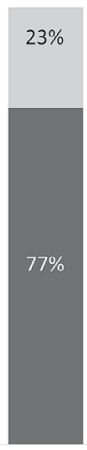

T1c

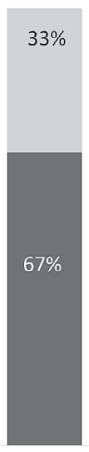

T2

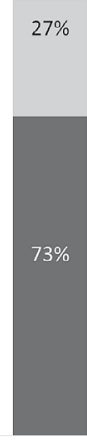

T3
Node-negative $\square$ Node-positive

FIGURE 1 Rates of one or more positive sentinel lymph nodes in 324 patients undergoing axillary surgery.

\section{Effect of Nodal Status on Adjuvant Therapies}

Data about adjuvant RT were available for all patients and about use of endocrine or systemic therapy, for 348 (95.6\%). Of patients having no axillary surgery, 10 of $33(30.3 \%)$ received whole-breast RT (WBRT) and 14 of 27 (51.9\%) with available data received endocrine therapy. Of 182 patients treated with BCS and SLNB, 120 (65.9\%) received WBRT; $18(9.9 \%)$, WBRT plus regional nodal irradiation (RNI); and $44(24.2 \%)$, no RT. Of 130 patients treated with mastectomy, 5 (3.9\%) received chest wall RT; 19 (14.6\%), chest wall RT plus RNI; and 106 (81.5\%), no RT. With respect to systemic 
TABLE II Preoperative factors associated with axillary metastases in 324 patients who received sentinel lymph node biopsy

\begin{tabular}{|c|c|c|c|}
\hline \multirow[t]{2}{*}{ Factor } & \multicolumn{3}{|c|}{ Multivariate analysis } \\
\hline & OR & $95 \% \mathrm{Cl}$ & $p$ Value \\
\hline Age & 0.9 & 0.9 to 1.1 & 0.97 \\
\hline $\begin{array}{l}\text { Preoperative tumour size } \\
\text { 0-1.0 cm } \\
1.1-2.0 \mathrm{~cm} \\
2.1-5.0 \mathrm{~cm} \\
>5.0 \mathrm{~cm}\end{array}$ & $\begin{array}{l}2.3 \\
3.9 \\
4.0\end{array}$ & $\begin{array}{l}\text { rence } \\
1.0 \text { to } 4.9 \\
1.8 \text { to } 8.5 \\
0.8 \text { to } 18.9\end{array}$ & 0.007 \\
\hline $\begin{array}{l}\text { Histologic type } \\
\text { Ductal } \\
\text { Any lobular component }\end{array}$ & 1.2 & $\begin{array}{l}\text { rence } \\
0.5 \text { to } 2.8\end{array}$ & 0.62 \\
\hline $\begin{array}{l}\text { Focality } \\
\text { Unifocal } \\
\text { Multifocal or multicentric }\end{array}$ & 1.7 & $\begin{array}{l}\text { rence } \\
0.8 \text { to } 3.7\end{array}$ & 0.16 \\
\hline $\begin{array}{l}\text { Grade } \\
\text { Low } \\
\text { Intermediate } \\
\text { High }\end{array}$ & $\begin{array}{l}1.4 \\
0.7\end{array}$ & $\begin{array}{l}\text { rence } \\
0.8 \text { to } 2.6 \\
0.3 \text { to } 1.7\end{array}$ & 0.21 \\
\hline
\end{tabular}

$\mathrm{OR}=$ odds ratio; $\mathrm{Cl}=$ confidence interval.

therapy in the 312 patients for whom those data were available, 225 (72.1\%) received endocrine therapy; $10(3.2 \%)$, chemotherapy and endocrine therapy; 67 (21.5\%), no systemic therapy; and 10 (3.2\%), unknown therapy.

Compared with patients having a negative nodal status, those with axillary metastases were significantly more likely to receive WBRT plus RNI if treated with BCS ( $53.1 \%$ vs. $0.7 \%, p<0.001$ ) or to receive chest wall RT plus RNI if treated with mastectomy ( $45.0 \%$ vs. $2.2 \%, p<0.001$, Table III). Of the 11 patients who received ALND, 6 also received RNI. Use of RNI was similar for those aged 70-74 years [WBRT plus RNI (BCS): $\mathrm{pN}+50.0 \%$ vs. pN- $1.4 \%$; chest wall RT plus RNI (mastectomy): $\mathrm{pN}+50.0 \%$ vs. $\mathrm{pN}-2.8 \%]$ and $75-79$ years [WBRT plus RNI (BCS): $\mathrm{pN}+66.7 \%$ vs. $\mathrm{pN}-0 \%$; chest wall RT plus RNI (mastectomy): $\mathrm{pN}+60.0 \%$ vs. $\mathrm{pN}-3.9 \%$ ]. Of those aged 80 or more years, use of RT was less common overall; $58.3 \%$ treated with BCS and $88.1 \%$ treated with mastectomy received no RT. In that age group, only 2 patients treated with BCS were $\mathrm{pN}+$, and both received only WBRT; use of RNI after mastectomy still differed by nodal status $(\mathrm{pN}+28.6 \%$ vs. $\mathrm{pN}-0 \%$ ).

Patients with axillary metastases were also significantly more likely to receive systemic therapy (endocrine: $\mathrm{pN}+$ $81.9 \%$ vs. $\mathrm{pN}-69.1 \%$; chemotherapy plus endocrine: $\mathrm{pN}+$ $6.9 \%$ vs. $\mathrm{pN}-2.1 \%$; none: $\mathrm{pN}+8.3 \%$ vs. $\mathrm{pN}-25.4 \% ; p=0.002$ ). In a stratification by surgical procedure, systemic therapy was more likely for patients in the mastectomy group who had axillary metastases $(p=0.02)$, with a trend seen in the BCS group ( $p=0.06$, Table III). In a stratification by age, the difference in the likelihood of endocrine therapy use for those aged $70-74$ years and $75-79$ years was similar $(70-74$ years: $\mathrm{pN}+86.3 \%$ vs. $\mathrm{pN}-74.2 \%$; $75-79$ years: $\mathrm{pN}+81.8 \%$ vs. $\mathrm{pN}-72.6 \%)$. Endocrine therapy use was again lower overall for those 80 or more years of age, with a larger difference seen by nodal status ( $\mathrm{pN}+68.7 \%$ vs. $\mathrm{pN}-50.0 \%$ ).
TABLE III Use of adjuvant therapy by nodal status in 312 patients with available data

\begin{tabular}{|c|c|c|c|}
\hline \multirow[t]{2}{*}{ Variable } & \multicolumn{2}{|c|}{ Nodal status } & \multirow{2}{*}{$\begin{array}{c}p \\
\text { Value }\end{array}$} \\
\hline & pN+ & $\mathrm{pN}-$ & \\
\hline \multicolumn{4}{|l|}{ Breast-conserving therapy } \\
\hline Patients ( $n$ ) & 150 & 32 & \\
\hline \multicolumn{4}{|l|}{ Radiation therapy $[n(\%)]$} \\
\hline Breast & $111(74.0)$ & $9(28.1)$ & \multirow{3}{*}{$<0.001$} \\
\hline Breast and axilla & $1(0.7)$ & $17(53.1)$ & \\
\hline None & $38(25.3)$ & $6(18.8)$ & \\
\hline \multicolumn{4}{|l|}{ Systemic therapy $[n(\%)]$} \\
\hline Endocrine & $110(73.3)$ & $28(87.4)$ & \multirow{4}{*}{0.06} \\
\hline Chemotherapy and endocrine & $3(2.0)$ & $2(6.3)$ & \\
\hline None & $33(22.0)$ & $2(6.3)$ & \\
\hline Unknown & $4(2.7)$ & 0 & \\
\hline \multicolumn{4}{|l|}{ Mastectomy } \\
\hline Patients $(n)$ & 90 & 40 & \\
\hline \multicolumn{4}{|l|}{ Radiation therapy $[n(\%)]$} \\
\hline Chest wall & $4(4.4)$ & 0 & \multirow{3}{*}{$<0.001$} \\
\hline Chest wall and axilla & $2(2.2)$ & $18(45.0)$ & \\
\hline None & $84(93.4)$ & $22(55.0)$ & \\
\hline \multicolumn{4}{|l|}{ Systemic therapy $[n(\%)]$} \\
\hline Endocrine & $56(62.2)$ & $31(77.5)$ & \multirow[t]{4}{*}{0.02} \\
\hline Chemotherapy and endocrine & $2(2.2)$ & $3(7.5)$ & \\
\hline None & $28(31.1)$ & $4(10.0)$ & \\
\hline Unknown & $4(4.4)$ & $2(5.0)$ & \\
\hline
\end{tabular}

\section{DISCUSSION}

In this large cohort of elderly patients with BCa monitored prospectively, more than $90 \%$ received SLNB, and rates of axillary metastases were $23 \%$, similar to rates observed in non-elderly patients ${ }^{12-14}$. Preoperative tumour size was the only independent predictor of nodal status, and yet significant rates of axillary metastasis were observed even for tumours $1 \mathrm{~cm}$ or less in size. Overall, ALND was uncommon and rarely performed based on sentinel node positivity. However, patients with positive nodes were more likely to receive nodal RT and adjuvant systemic therapy. Half the patients with axillary metastases received nodal RT, and compared with only $75 \%$ of node-negative patients, more than $90 \%$ received adjuvant endocrine therapy. Together, those findings demonstrate that omitting SLNB would result in the loss of staging information that currently plays a role in the adjuvant treatment of elderly patients.

One subset of patients who might arguably forego SLNB are those with a low likelihood of axillary metastases. A strength of our analysis examining factors associated with a positive sentinel node was that preoperatively known variables were included. Preoperative tumour size was significantly associated with nodal status, consistent with previous literature ${ }^{12-16}$. However, only patients with lesions of $5 \mathrm{~mm}$ or less had a less than $10 \%$ absolute rate of axillary metastases, which is the known false-negative rate for SLNB in patients with cN0 status ${ }^{17}$. In our study, the 
group with lesions $5 \mathrm{~mm}$ or less was a small one, making it difficult to draw definitive conclusions, although such patients can likely be considered to have a very low risk of axillary metastases on SLNB. Another consideration is a patient's ability to tolerate a general anesthetic, which is typically required for axillary surgery. We did find that those treated without axillary surgery were older and more likely to undergo BCS (which can be performed under local anesthesia) rather than mastectomy.

Other studies have examined predictors of nodal positivity specifically in elderly patients. In 700 elderly patients with ER+ BCa from the NAFTA trial, Chagpar et al. ${ }^{18}$ found that age [odds ratio (OR): $1.08 ; p=0.03$ ], tumour size (OR: $1.60 ; p=0.009$ ), and lymphovascular invasion (OR: 3.56 ; $p=0.005$ ) were significant predictors of axillary metastases on multivariate analysis. Lymphovascular invasion is not routinely reported on preoperative core biopsies at our institution and therefore cannot realistically be used as a selection criterion for SLNB. In a review of 82,555 patients 70 years of age and older with $\mathrm{cN} 0 \mathrm{ER}+\mathrm{BCa}$ from the U.S. National Cancer Database (NCDB), $15.3 \%$ of those who underwent axillary surgery $(10,979$ of 71,834$)$ were $\mathrm{pN}+$. The authors of that study developed a clinical prediction rule, which identified $2 \mathrm{~cm}$ or smaller grade $\mathrm{I}$ or $1 \mathrm{~cm}$ or smaller grade II tumours as having a less than $10 \%$ probability of a positive sentinel node ${ }^{19}$. Among the patients in our study who received axillary surgery, $25 \%$ had $2 \mathrm{~cm}$ or smaller grade I tumours, $11 \%$ of whom had axillary metastases; and $15 \%$ had $1 \mathrm{~cm}$ or smaller grade II tumours, $14 \%$ of whom had axillary metastases. Based on those criteria, a substantial proportion of elderly patients could therefore have avoided axillary surgery, although nodal positivity rates in our population were above $10 \%$ in both subgroups. It is difficult to know whether that observation is attributable to the relatively small sample size or legitimate differences in rates of axillary metastases for patients with those preoperative parameters. For example, $42 \%$ of our patients with $1 \mathrm{~cm}$ or smaller grade II lesions on preoperative assessment were upsized to tumours larger than $1 \mathrm{~cm}$ on final pathology, which might differ from the preoperative compared with postoperative sizing discrepancy rates in the NCDB patients. Until those uncertainties are further clarified, we would hesitate to apply the suggested criteria to our population.

Another important consideration beyond likelihood of nodal positivity is how axillary staging information affects additional treatment. With respect to locoregional therapies, rates of ALND were low overall, including in patients with positive sentinel nodes. The Choosing Wisely guidelines are based on level I evidence supporting the lack of survival benefit with ALND in the elderly population; adoption of those data is reflected in our practice ${ }^{2,3}$. However, about half the patients found to be $\mathrm{pN}+$ received nodal RT. The MA.20 trial investigated the effects of RNI in 1832 patients with early-stage, primarily $\mathrm{pN}+$, BCa treated with BCs, finding no overall or BCa-specific survival benefit for WBRT plus RNI compared with WBRT alone, and yet a small but significant disease-free survival benefit was observed at 10 years $(82.0 \% \text { vs. } 77.0 \%, p=0.01)^{9}$. The European Organisation for Research and Treatment of Cancer 22922/10925 trial included 4004 patients with $\mathrm{pN}+$ or high-risk node-negative disease treated with either BCS or mastectomy and demonstrated a disease-free survival benefit $(72.1 \%$ vs. $69.1 \%, p=0.04)$, a distant disease-free survival benefit $(78.0 \%$ vs. $75.0 \%, p=0.02)$, and а вса mortality benefit ( $12.5 \%$ vs. $14.4 \%, p=0.02)$, with a borderline overall survival benefit $(82.3 \%$ vs. $80.7 \%, p=0.06$ ) with nodal $\mathrm{RT}^{10}$. However, women more than 70 years of age were underrepresented in those trials (median age: 53-54 years), and neither trial included age in subgroup analyses $^{9,10}$. The ongoing Canadian Cancer Trials Group MA.39 study (TAILOR RT) might provide further insight in patients with genomic low-risk disease (see NCT03488693 at https://ClinicalTrials.gov/), although elderly patients will likely still be under-enrolled.

The MA.20 and European Organisation for Research and Treatment of Cancer 22922/10925 trials have significantly influenced radiation oncology practice patterns at our institution in younger women. Our findings demonstrate that their application in elderly women is more variable, consistent with population-based data from the NCDB, which showed that, after the publication of those trials, rates of nodal RT increased to $42.5 \%$ from $33.9 \%$ in women 70-89 years of age with T1-2N1 BCa (2004-2010 vs. 20112013, $p=0.03)^{20}$. Future study is needed to delineate the benefit gained from nodal RT in elderly patients, although at present a large proportion of those patients receive that therapy at our institution, suggesting that many providers perceive an oncologic benefit. In addition, future Canadian population-based efforts should focus on delineating factors associated with use of nodal RT in elderly patients with pN+ disease. In the 2011-2013 NCDB cohort, the most influential modifier of nodal RT use was a higher number of positive nodes (OR: $1.521 ; p<0.001$ ), which requires SLNB to determine. The presence of 2 or more high-risk features (ER negativity, high tumour grade, lymphovascular invasion, and medial or central tumour location; OR: 1.296; $p=0.007$ ) was also associated with nodal RT use $^{20}$. Those variables could be further explored as selection criteria for SLNB in patients who would be considered for nodal RT based on overall risk profile.

An unexpected finding in our data was that nodal status not only affected locoregional therapy, but also the use of systemic therapy. Given low rates of chemotherapy in this elderly population, those results were driven primarily by differences in adjuvant endocrine therapy. The survival benefit for adjuvant tamoxifen across all subgroups of ER+ BCa is well-established ${ }^{21}$. Five years of adjuvant aromatase inhibitor therapy provides a further disease-free survival benefit and decreased incidences of distant metastases and contralateral $\mathrm{BCa}$, especially in postmenopausal women more than 65 years of age ${ }^{22,23}$. Thus, adjuvant endocrine therapy is recommended for $\mathrm{ER}+\mathrm{BCa}$ regardless of nodal status. However, adherence rates are as low as $50 \%-74 \%^{3,24-27}$, in part because of the known adverse effects of aromatase inhibitors, including arthralgias, osteoporosis, fractures, hypertension, and perhaps ischemic cardiovascular events ${ }^{3,28-31}$. When considering the risk-benefit ratio of adjuvant endocrine therapy, providers might be more likely to strongly recommend-and patients more likely to agree to-endocrine therapy in the setting of axillary metastases because of the higher perceived risk of future recurrence and mortality. Although the absolute difference in systemic 
therapy use was modest in our population $(\sim 17 \%)$, given the robust risk reduction effects of adjuvant endocrine therapy, the potential oncologic impact of that finding warrants future investigation. Moreover, recent updates to the American Society of Clinical Oncology practice guidelines now recommend that patients with node-positive ER+BCa receive extended adjuvant endocrine therapy for a total of 10 years ${ }^{11}$. Given those new guidelines, nodal status could play an even larger role in adjuvant endocrine therapy recommendations in future.

Our study has some limitations. Adjuvant treatment recommendations can differ according to institutional norms, and our findings might not be applicable in all centres. Given the small number of patients with $\mathrm{pN}+$ disease in the study, we were unable to investigate other clinicopathologic factors associated with the use of adjuvant therapies. Our findings suggest using caution in routinely omitting SLNB, but we cannot draw conclusions about which subgroups of elderly patients will benefit most from the procedure. Our exploratory subgroup analysis by age found that use of both adjuvant RT and endocrine therapy is lower overall for those 80 years of age and older; omission of SLNB in that group would therefore have a lesser effect on treatment decisions. Our "unknown nodal status" group was small, with significantly different patient characteristics, precluding definitive conclusions about how radiation and medical oncologists might select patients for adjuvant therapies if SLNB were to be routinely omitted. Some studies have investigated the use of less-invasive axillary staging methods such as axillary ultrasonography, with promising results ${ }^{32,33}$, and that technique is currently being studied in randomized controlled trials (See NCT02167490 and NCT01821768 at https://ClinicalTrials.gov/.). Such information was not available for our cohort and could be a worthwhile area of future study. Patient comorbidities were not accounted for in this study. A previous analysis reflecting a similar population from our province (722 elderly patients with BCa treated with lumpectomy between 1999 and 2009) found a score of 0 on the Charlson comorbidity index in $69 \%$ and of 1 in $23 \%$ - overall, a fairly healthy group. Notably, use of RT in that population differed by Charlson comorbidity index $(p=0.0002)$, suggesting that patient comorbidities do influence adjuvant treatment decisions ${ }^{34}$. Finally, long-term oncologic outcomes were not available for this cohort. To determine the true clinical effect of omitting SLNB in this population, further study will have to evaluate the effects on recurrence and survival of the various adjuvant treatments observed in our study.

\section{CONCLUSIONS}

In a large cohort of elderly patients with clinically node-negative ER+ BCa, nearly 1 in 4 had axillary metastases on SLNB. Tumour size was the only significant preoperative predictor of a positive nodal status, and yet only tumours $5 \mathrm{~mm}$ or smaller in size were associated with a less than $10 \%$ rate of axillary metastases. Patients with axillary metastases were significantly more likely to receive adjuvant nodal RT and endocrine therapy regardless of treatment with BCS or mastectomy. With the omission of SLNB, staging information that currently plays a role in treatment would be lost. Further study is needed to determine the long-term oncologic implications. At present, we advocate for multidisciplinary evaluation on a case-by-case basis to review how nodal staging information might affect a patient's adjuvant treatment, before SLNB is omitted.

\section{ACKNOWLEDGMENTS}

The authors acknowledge the support of the BC Cancer Surgical Oncology Network for statistical analysis and the contributions of Lovedeep Gondora MS and Nuria Chapinal PhD.

\section{CONFLICT OF INTEREST DISCLOSURES}

We have read and understood Current Oncology's policy on disclosing conflicts of interest, and we declare that we have none.

\section{AUTHOR AFFILIATIONS}

*Department of Surgery, Foothills Medical Centre, University of Calgary, Calgary, AB; and ${ }^{\dagger}$ Department of Surgery, BC Cancer, University of British Columbia, ${ }^{\ddagger}$ Department of Surgery, Providence Health Care, University of British Columbia, and ${ }^{\S}$ Population Oncology, BC Cancer, Vancouver, BC.

\section{REFERENCES}

1. Choosing Wisely. Society of Surgical Oncology: Don't routinely use sentinel node biopsy in clinically node negative women $\geq 70$ years of age with early stage hormone receptor positive, HER2 negative invasive breast cancer [Web page]. Philadelphia, PA: ABIM Foundation; 2019. [Available at: https://www. choosingwisely.org/clinician-lists/sso-sentinel-node-biopsyin-node-negative-women-70-and-over/; cited 23 February 2020]

2. Martelli G, Boracchi P, Ardoino I, et al. Axillary dissection versus no axillary dissection in older patients with T1N0 breast cancer: 15-year results of a randomized controlled trial. Ann Surg 2012;256:920-4.

3. Rudenstam CM, Zahrieh D, Forbes JF, et al. on behalf of the International Breast Cancer Study Group. Randomized trial comparing axillary clearance versus no axillary clearance in older patients with breast cancer: first results of International Breast Cancer Study Group trial 10-93. J Clin Oncol 2006;24:337-44.

4. Mandelblatt JS, Edge SB, Meropol NJ, et al. Sequelae of axillary lymph node dissection in older women with stage 1 and 2 breast carcinoma. Cancer 2002;95:2445-54.

5. McMahon LE, Gray RJ, Pockaj BA. Is breast cancer sentinel lymph node mapping valuable for patients in their seventies and beyond? Am J Surg 2005;190:366-70.

6. DiFronzo LA, Hansen NM, Stern SL, Brennan MB, Giuliano AE. Does sentinel lymphadenectomy improve staging and alter therapy in elderly women with breast cancer? Ann Surg Oncol 2000;7:406-10.

7. Hieken TJ, Nettnin S, Velasco JM. The value of sentinel lymph node biopsy in elderly breast cancer patients. Am J Surg 2004;188:440-2.

8. Boughey JC, Haffty BG, Habermann EB, et al. Has the time come to stop surgical staging of the axilla for all women age 70 years or older with hormone receptor-positive breast cancer? Ann Surg Oncol 2017;24:614-17.

9. Whelan TJ, Olivotto IA, Parulekar WR, et al. Regional nodal irradiation in early-stage breast cancer. N Engl J Med 2015; 373:307-16.

10. Poortmans PM, Collette S, Kirkove C, et al. Internal mammary and medial supraclavicular irradiation in breast cancer. N Engl J Med 2015;373:317-27.

11. Burstein HJ, Lacchetti C, Anderson H, et al. Adjuvant endocrine therapy for women with hormone receptor-positive breast cancer: ASCO clinical practice guideline focused update. J Clin Oncol 2019;37:423-38. 
12. Bevilacqua JLB, Kattan MW, Fey JV, Cody HS 3rd, Borgen PI, Van Zee KJ. Doctor, what are my chances of having a positive sentinel node? A validated nomogram for risk estimation. J Clin Oncol 2007;25:3670-9.

13. Carmichael AR, Aparanji K, Nightingale P, Bopari R, Stonelake PS. A clinicopathological scoring system to select breast cancer patients for sentinel node biopsy. Eur J Surg Oncol 2006;32:1170-4.

14. Chen JY, Chen JJ, Yang BL, et al. Predicting sentinel lymph node metastasis in a Chinese breast cancer population: assessment of an existing nomogram and a new predictive nomogram. Breast Cancer Res Treat 2012;135:839-48.

15. Viale G, Zurrida S, Maiorano E, et al. Predicting the status of axillary sentinel lymph nodes in 4351 patients with invasive breast carcinoma treated in a single institution. Cancer 2005; 103:492-500.

16. Dihge L, Bendahl PO, Ryden L. Nomograms for preoperative prediction of axillary nodal status in breast cancer. Br J Surg 2017;104:1494-505.

17. Krag DN, Anderson SJ, Julian TB, et al. on behalf of the National Surgical Adjuvant Breast and Bowel Project. Technical outcomes of sentinel-lymph-node resection and conventional axillary-lymph-node-dissection in patients with clinically node-negative breast cancer: results from the NSABP B-32 randomised phase III trial. Lancet Oncol 2007;8:881-8.

18. Chagpar AB, McMaster KM, Edwards MJ on behalf of the North American Fareston Tamoxifen Adjuvant trial. Can sentinel node biopsy be avoided in some elderly breast cancer patients? Ann Surg 2009;249:455-60.

19. Welsh JL, Hoskin TL, Day CN, Habermann EB, Goetz MP, Boughey JC. Predicting nodal positivity in women 70 years of age and older with hormone receptor-positive breast cancer to aid incorporation of a Society of Surgical Oncology Choosing Widely guideline into clinical practice. Ann Surg Oncol 2017;24:2881-8.

20. Molitoris JK, Diwanji T, Snider JW, et al. Increasing utilization of regional nodal irradiation in elderly node-positive women and declining emphasis on demographic factors. Breast Cancer Res Treat 2017;165:669-76.

21. Davies C, Godwin J, Gray R, et al. on behalf of the Early Breast Cancer Trialists' Collaborative Group. Relevance of breast cancer hormone receptors and other factors to the efficacy of adjuvant tamoxifen: patient-level meta-analysis of randomised trials. Lancet 2011;378:771-84.

22. Cuzick J, Sestak I, Baum M, et al. on behalf of the ATAC/LATTE investigators. Effect of anastrozole and tamoxifen as adjuvant treatment for early-stage breast cancer: 10-year analysis of the ATAC trial. Lancet Oncol 2010;11:1135-41.

23. Thurlimann B, Keshaviah A, Coates AS, et al. on behalf of the Breast International Group 1-98 Collaborative Group. A comparison of letrozole and tamoxifen in postmenopausal women with early breast cancer. N Engl J Med 2005;353:2747-57.

24. Farias AJ, Du XL. Association between out-of-pocket costs, race/ethnicity and adjuvant endocrine therapy adherence among Medicare patients with breast cancer.JClin Oncol2017; 35:86-95.

25. Owusu C, Buist DS, Field TS, et al. Predictors of tamoxifen discontinuation among older women with estrogen receptor-positive breast cancer. J Clin Oncol 2008;26:549-55.

26. Murphy CC, Bartholomew LK, Carpentier MY, Bluethmann SM, Vernon SW. Adherence to adjuvant hormonal therapy among breast cancer survivors in clinical practice: a systematic review. Breast Cancer Res Treat 2012;134:459-78.

27. Brier MJ, Chambless DL, Chen J, Mao JJ. Ageing perceptions and non-adherence to aromatase inhibitors among breast cancer survivors. Eur J Cancer 2018;91:145-52.

28. Muss HB, Tu D, Ingle JN, et al. Efficacy, toxicity, and quality of life in older women with early-stage breast cancer treated with letrozole or placebo after 5 years of tamoxifen: NCIC CTG Intergroup trial MA.17. J Clin Oncol 2008;26:1956-64.

29. Becker T, Lipscombe L, Narod S, Simmons C, Anderson GM, Rochon PA. Systematic review of bone health in older women treated with aromatase inhibitors for early-stage breast cancer. J Am Geriatr Soc 2012;60:1761-7.

30. Dowsett M, Cuzick J, Ingle J, et al. Meta-analysis of breast cancer outcomes in adjuvant trials of aromatase inhibitors versus tamoxifen. J Clin Oncol 2010;28:509-18.

31. Amir E, Seruga B, Niraula S, Carlsson L, Ocana A. Toxicity of adjuvant endocrine therapy in postmenopausal breast cancer patients: a systematic review and meta-analysis. JNatl Cancer Inst 2011;103:1299-309.

32. Tucker NS, Cyr AT, Ademuyiwa FO, et al. Axillary ultrasound accurately excludes clinically significant lymph node disease in patients with early stage breast cancer. Ann Surg 2016;264:1098-102.

33. Chowdhury D, Drehuta I, Bhattacharya S. Surgical staging of the axilla: is it on its way out? A retrospective study and review of the literature. Clin Breast Cancer 2017;17:578-80.

34. Nichol AM, Chan EK, Lucas S, et al. The use of hormone therapy alone versus hormone therapy and radiation therapy for breast cancer in elderly women: a population-based study. Int J Radiat Oncol Biol Phys 2017;98:829-39. 